\title{
Survival, growth, and maturation of secondary follicles from prepubertal, young, and older adult rhesus monkeys during encapsulated three-dimensional culture: effects of gonadotropins and insulin
}

\author{
Jing $\mathrm{Xu}^{1}$, Marcelo P Bernuci ${ }^{1}$, Maralee S Lawson ${ }^{1}$, Richard R Yeoman ${ }^{1}$, Thomas E Fisher ${ }^{1,2}$, \\ Mary B Zelinski ${ }^{1,2}$ and Richard L Stouffer ${ }^{1,2}$ \\ ${ }^{1}$ Division of Reproductive Sciences, Oregon National Primate Research Center, Oregon Health \& Science University, \\ 505 Northwest 185th Avenue, Beaverton, Oregon 97006, USA and ${ }^{2}$ Department of Obstetrics and Gynecology, \\ Oregon Health \& Science University, 3181 SW Sam Jackson Park Road, Portland, Oregon 97239, USA
}

Correspondence should be addressed to M B Zelinski at Division of Reproductive Sciences, Department of Obstetrics and Gynecology, Oregon National Primate Research Center, Oregon Health \& Science University; Email: zelinski@ohsu.edu

\begin{abstract}
A three-dimensional culture system supports the development of primate preantral follicles to the antral stage with appreciable steroid production. This study assessed i) whether in vitro developmental competence of follicles is age dependent, ii) the role of gonadotropins and insulin in supporting folliculogenesis, and iii) anti-Müllerian hormone (AMH) and vascular endothelial growth factor (VEGF) production by growing follicles. Ovaries were obtained from prepubertal, young, and older adult rhesus macaques. Secondary follicles were encapsulated into alginate beads and cultured individually for 40 days in media containing 0.05 or $5 \mu \mathrm{g} / \mathrm{ml}$ insulin, with or without recombinant human $(\mathrm{rh}) \mathrm{FSH}(500 \mathrm{mIU} / \mathrm{ml})$. No follicles survived in the culture without rhFSH. In the presence of rhFSH, survival was lower for follicles from older animals, whereas growth, i.e. follicle diameter, was less by day 40 for follicles from prepubertal animals. The surviving follicles were categorized as no-grow (NG; $\leq 250 \mu \mathrm{m})$, slow-grow (SG; 250-500 $\mu \mathrm{m}$ ), and fast-grow (FG; $\geq 500 \mu \mathrm{m})$ according to their diameters. SG follicles cultured with $5 \mu \mathrm{g} / \mathrm{ml}$ insulin produced more ovarian steroids than those cultured with $0.05 \mu \mathrm{g} / \mathrm{ml}$ insulin by week 5. SG and FG follicles produced more AMH and VEGF than the NG, and levels peaked at weeks 2 and 5 respectively. After $100 \mathrm{ng} / \mathrm{ml}$ rh chorionic gonadotropin treatment for $34 \mathrm{~h}$, more healthy oocytes were retrieved from young adults whose follicles were cultured with $5 \mu \mathrm{g} / \mathrm{ml}$ insulin. This culture system offers an opportunity to characterize the endocrine and paracrine function of primate follicles that influence follicle growth and oocyte maturation.
\end{abstract}

Reproduction (2010) 140 685-697

\section{Introduction}

Early follicular development is a dynamic process that is regulated by complex interactions between gonadotropins and local factors (Gougeon 1996). Although progress in understanding early folliculogenesis has been made, particularly in mice through gene manipulation (Matzuk 2000, Drummond 2006), the regulation and dynamics of primate folliculogenesis, aside from phenotypic analysis in human (Chand et al. 2010, Ewens et al. 2010), remain poorly understood. Recently, feasibility of using tissue engineering principles to develop a three-dimensional (3D) matrix that supports follicle development was successfully demonstrated in mice (Xu et al. 2006, West et al. 2007). This 3D approach yielded antral follicles with mature oocytes that, when inseminated in vitro, fertilized and, following embryo transfer, produced live offspring (Xu et al. 2006).
Applying encapsulated 3D follicle culture to the primate, it was possible to grow rhesus monkey preantral follicles through the small antral stage with appreciable levels of ovarian steroid production (Xu et al. 2009a). This technique provides a valuable in vitro model to study the process and regulation of folliculogenesis in intact individual follicles in primates. However, further advances are needed to develop an adequate milieu for macaque follicular growth and differentiation that provides oocytes competent for fertilization and development. The major challenges include i) the length of time for a follicle to grow from preantral to the small antral stage at which it can be selected for final maturation, which is estimated to be 65 days in vivo (Gougeon 1998), and ii) the large size of a mature preovulatory follicle with a fertilizable oocyte, which is $3-6 \mathrm{~mm}$ in diameter in macaques. 
Although full knowledge of the milieu for follicle growth in vivo is still lacking, there is evidence that the adequate levels of certain hormones are essential for the growth of healthy follicles in vitro (Picton et al. 2008). The pituitary gonadotropin, $\mathrm{FSH}$, may promote, if not be essential for, follicle growth in culture systems. For example, FSH administration not only maintained the morphological integrity of caprine preantral follicles, but also stimulated the activation of primordial follicles and the growth of activated follicles in the culture (Matos et al. 2007). In 3D matrix systems, FSH increased the diameter of mouse (Xu et al. 2006), monkey (Xu et al. 2009a), and human (Xu et al. 2009b) follicles in vitro. LH may also enable primary and secondary follicles to respond to later $\mathrm{LH}$-dependent growth, by inducing early differentiation of the theca cells, during follicle culture in mice (Cortvrindt et al. 1998, Wu et al. 2000). At later stages of culture, monkey follicles in the media supplemented with $\mathrm{LH}$ tended to produce more estradiol $\left(E_{2}\right)$, which may be attributed to increased presence of theca cell (Xu et al. 2009a). There is also an increasing body of evidence that insulin may stimulate follicular growth in vitro (Wright et al. 1999). Insulin, as a survival factor, reduces the proportion of atretic follicles in early stages of human follicle culture, hence improving the overall viability of the follicles (Louhio et al. 2000).

It is also likely that paracrine factors modulate preantral and antral follicle development in primates (Albertini et al. 2001, Eppig 2001). Growing evidence suggests that anti-Müllerian hormone (AMH) plays a key role in the early stages of folliculogenesis (Durlinger et al. 2002, Carlsson et al. 2006). AMH could affect early stages of human follicular development by enhancing recruitment, survival, and/or growth during ovarian tissue culture (Schmidt et al. 2005). Also, the angiogenesis process is a fundamental activity in the ovary, specifically during follicular growth, atresia, ovulation, and luteinization. Angiogenic factors produced by the follicle, such as vascular endothelial growth factor (VEGF), may promote vascular changes during follicle growth (Hazzard \& Stouffer 2000). However, they may also have other roles, as suggested by evidence that VEGF maintains follicular ultrastructural integrity and promotes the growth of caprine preantral follicles during ovarian tissue culture (Bruno et al. 2009). Thus, AMH and VEGF may be valuable markers of follicle maturation and function. However, knowledge surrounding the dynamics of $\mathrm{AMH}$ and VEGF production and regulation in the growing follicles is unknown, especially in primates.

Using encapsulated 3D culture of nonhuman primate preantral follicles, this study assessed whether the developmental competence of follicles was dependent upon maternal age, and evaluated the role of gonadotropins, FSH alone or with sequential addition of $\mathrm{LH}$, and insulin to support folliculogenesis. Additionally, studies were conducted to investigate the ovarian steroids (androstenedione, $\mathrm{A} 4 ; \mathrm{E}_{2} ;$ and progesterone, $\mathrm{P}_{4}$ ) and paracrine factors (AMH and VEGF) produced by individual cultured follicles that may influence follicle growth and health.

\section{Results}

\section{Follicle survival and growth}

Total and average number of secondary follicles isolated from different age groups of animal and the follicle distribution in different culture conditions are summarized in Table 1. Follicle survival could be identified clearly with viable follicles exhibiting an intact basement membrane versus atretic follicles having dark granulosa cells and denuded oocytes (Xu et al. 2009a). By culture week 2, all follicles cultured in the absence of FSH underwent atresia regardless of animal age and culture condition, whereas more than $50 \%$ of the follicles cultured with FSH survived.

For follicles cultured in the presence of FSH and high-dose insulin, there was no difference in survival rate between prepubertal $(59 \pm 8 \%)$ and young adult $(55 \pm 11 \%)$ animals by culture week 5 . However, the survival rate was less $(P<0.05)$ for follicles from older adult animals $(15 \pm 5 \%$ ) by culture week 5 than those from prepubertals and young adults. The lower insulin dose and LH administration had no effect on follicle survival for animals in all the three age groups (data not shown).

At the beginning of the culture, follicle diameters did not differ among the age groups and culture conditions (data not shown). However, during culture, three distinct cohorts of follicles were observed based on their growth rate. For example, for follicles cultured with FSH and high-dose insulin (Fig. 1A), a cohort remained similar in size to the initial secondary follicles without significant change in diameters through 5 weeks of culture, ranging from $148 \pm 3$ to $195 \pm 40 \mu \mathrm{m}$ in young adult animals

Table 1 Total and average yield of follicles from animals of different age groups and their assignment to experimental culture conditions.

\begin{tabular}{|c|c|c|c|c|c|c|c|}
\hline \multirow[b]{2}{*}{$\begin{array}{l}\text { Age group } \\
(n=3 / \text { group })\end{array}$} & \multirow[b]{2}{*}{$\begin{array}{c}\text { Total yield } \\
(\text { mean } \pm \text { s.E.M. })\end{array}$} & \multicolumn{2}{|c|}{ Without FSH } & \multicolumn{4}{|c|}{ With FSH } \\
\hline & & $\begin{array}{l}5 \mu \mathrm{g} / \mathrm{ml} \\
\text { insulin }\end{array}$ & $\begin{array}{l}0.05 \mu \mathrm{g} / \mathrm{ml} \\
\text { insulin }\end{array}$ & $\begin{array}{l}5 \mu \mathrm{g} / \mathrm{ml} \\
\text { insulin }\end{array}$ & $\begin{array}{c}5 \mu \mathrm{g} / \mathrm{ml} \\
\text { insulin + LH }\end{array}$ & $\begin{array}{l}0.05 \mu \mathrm{g} / \mathrm{ml} \\
\text { insulin }\end{array}$ & $\begin{array}{c}0.05 \mu \mathrm{g} / \mathrm{ml} \\
\text { insulin }+\mathrm{LH}\end{array}$ \\
\hline Prepubertal & $204(68 \pm 4)$ & 24 & 12 & 48 & 48 & 36 & 36 \\
\hline Young adult & $324(108 \pm 0)$ & 24 & 12 & 72 & 72 & 72 & 72 \\
\hline Older adult & $360(120 \pm 7)$ & 24 & 12 & 84 & 84 & 84 & 72 \\
\hline
\end{tabular}


(Fig. 1B), and were termed 'no-grow (NG)' follicles. Another cohort doubled $(P<0.05)$ their diameters, from $158 \pm 8$ to $376 \pm 25 \mu \mathrm{m}$ in young adult animals (Fig. 1C), and were termed 'slow-grow (SG)' follicles. Finally, another group of follicles increased $(P<0.05)$ their diameters by a minimum of threefold, from $165 \pm 8$ to $667 \pm 58 \mu \mathrm{m}$ in young adult animals (Fig. 1D), and were termed 'fast-grow (FG)' follicles. The NG follicles from prepubertal and older, as well as from young adults were evident in all ovarian samples (Fig. 1B). The SG pattern also appeared in follicles from both young and older adult animals (Fig. 1C), but the SG follicles from young adults reached larger $(P<0.05)$ diameters by culture week 5 than those from the prepubertal group (Fig. 1C). The FG follicles were only collected from young adult animals and represented $43 \%$ of the total cohort; whereas $9 \%$ were NG and $48 \%$ were SG follicles. The percentage of NG and SG follicles were 14 and $86 \%$ respectively for the prepubertal group. In contrast, there was a greater proportion of NG (69\%) and a smaller proportion of SG follicles (31\%) collected from the older adult group (Fig. 1A). An antral cavity was evident within 3 weeks of culture for all the SG and FG follicles.

The lower dose of insulin did not alter the growth rate of the NG follicles (Fig. 2A) and SG follicles (Fig. 2B) from young adult animals, as well as from the prepubertal and older adult monkeys (data not shown).

A

\begin{tabular}{lccc}
\multicolumn{4}{c}{ Number of surviving follicles } \\
\hline & $\begin{array}{c}\text { No- } \\
\text { grow }\end{array}$ & $\begin{array}{c}\text { Slow- } \\
\text { grow }\end{array}$ & $\begin{array}{c}\text { Fast- } \\
\text { grow }\end{array}$ \\
\hline Prepubertal & 4 & 24 & 0 \\
Young adult & 4 & 19 & 17 \\
Older adult & 9 & 4 & 0 \\
\hline
\end{tabular}
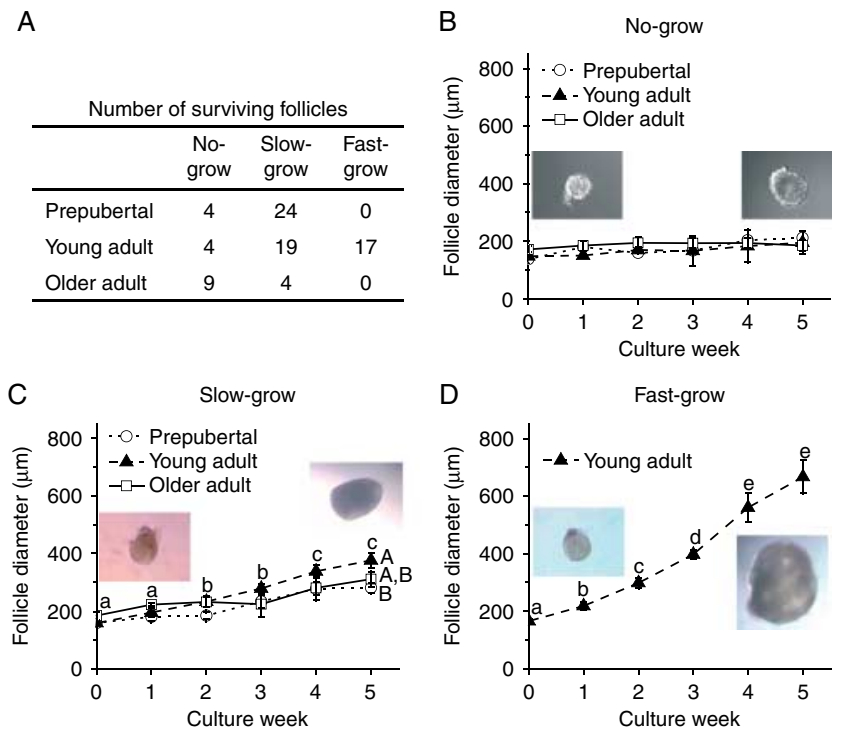

$-250 \mu \mathrm{m}$

Figure 1 Macaque follicle survival and growth in media containing FSH and high-dose insulin, without LH supplementation at day 30. Number of three cohorts of surviving follicles from different age groups at week 5 of culture (panel A) and the growth patterns for the no-grow (panel B), slow-grow (panel C), and fast-grow (panel D) follicles from prepubertal $(n=3)$, young $(n=3)$, and older $(n=3)$ adult animals during culture. Significant differences over time (lowercase) or between the age groups (uppercase) are indicated by different letters $(P<0.05)$. Data are presented as the mean \pm s.E.M. Representative follicle pictures in panels B-D are from culture day 1 (left) and day 40 (right). Scale bar $=250 \mu \mathrm{m}$.
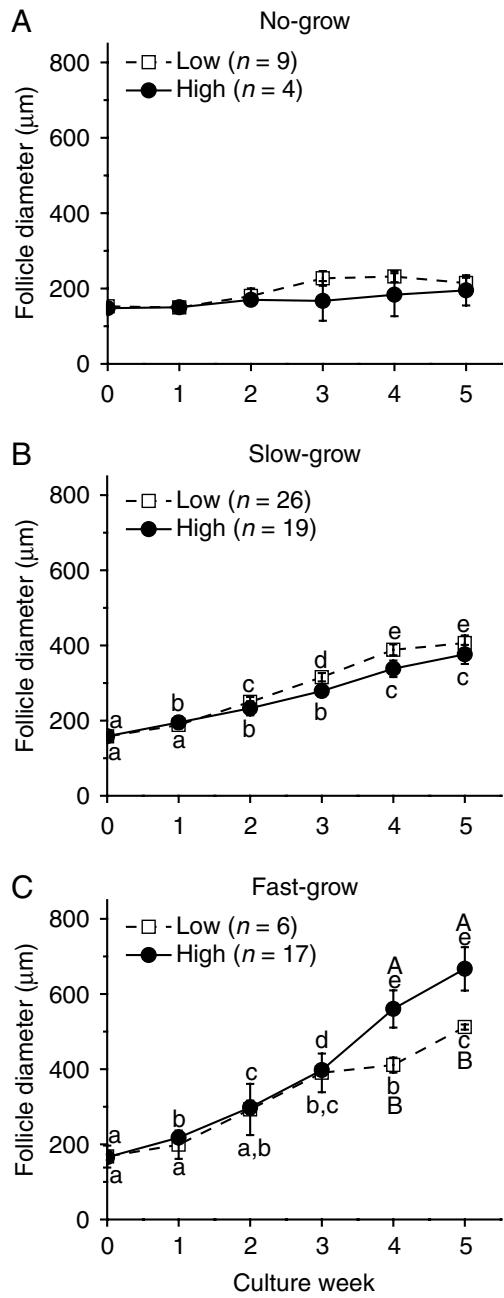

Figure 2 Insulin effect on patterns of macaque follicle growth. Growth patterns of no-grow (panel A), slow-grow (panel B), and fast-grow (panel C) follicles from young adult animals $(n=3)$ during culture in media containing FSH and either low- or high-dose insulin, without LH supplementation at day 30. Significant differences over time (lowercase) or between the insulin dosage groups (uppercase) are indicated by different letters $(P<0.05)$. Data are presented as the mean \pm S.E.M.

However, even though the FG follicles maintained a similar growth rate between the low- and high-dose insulin-treated groups for the first 3 weeks of culture, the follicle diameters became larger $(P<0.05)$ in the highdose insulin cultures than in the low-dose cultures on weeks 4 and 5 (Fig. 2C).

LH supplementation at culture day 30 did not promote further growth of the follicles regardless of animal age and culture condition (data not shown).

\section{Oocyte maturation and diameter}

Following exposure of antral follicles (SG and FG) to recombinant human chorionic gonadotropin (rhCG), healthy, as well as degenerate (dark and condensed cytoplasm), oocytes were obtained during retrieval. There were also follicles that did not yield oocytes. 
Table 2 Characteristics of oocytes retrieved from macaque antral follicles on day 40 of 3-dimensional culture, $34 \mathrm{~h}$ after addition of recombinant human chorionic gonadotropin (rhCG), for different age groups.

\begin{tabular}{|c|c|c|c|c|c|}
\hline \multirow[b]{2}{*}{ Age group } & \multicolumn{4}{|c|}{ Number $(n)$ of } & \multirow{2}{*}{$\frac{\text { Diameter }(\mu \mathrm{m})^{*}}{\text { GV-intact oocytes }}$} \\
\hline & Follicles harvested & Oocytes retrieved & Degenerate oocytes & GV-intact oocytes & \\
\hline Prepubertal & 14 & 8 & 5 & 3 & $69 \pm 10^{\mathrm{a}}$ \\
\hline $\begin{array}{l}\text { Young adult } \\
\text { (slow-grow) } \\
\text { (fast-grow) }\end{array}$ & $\begin{array}{l}25 \\
10\end{array}$ & $\begin{array}{r}13 \\
7\end{array}$ & 7 & $\begin{array}{l}6 \\
6\end{array}$ & $\begin{array}{l}85 \pm 3^{a, b} \\
99+4^{b}\end{array}$ \\
\hline Older adult & 5 & 2 & 0 & 2 & $71 \pm 27$ \\
\hline
\end{tabular}

*Values are the mean \pm S.E.M. ${ }^{\text {a,b }}$ Different letters indicate significant differences within the column $(P<0.05)$.

Despite rhCG treatment, all the healthy oocytes remained at the germinal vesicle (GV)-intact stage at retrieval (Table 2), and no oocytes matured to metaphase $\mathrm{I}(\mathrm{MI})$ or MII stage during $48 \mathrm{~h}$ in vitro after removal from the follicles. Oocytes retrieved from follicles under all the culture conditions were combined for analysis of oocyte maturation among the different age groups. Of the 20 oocytes retrieved from the young adult group, $60 \%$ were GV-intact oocytes. Furthermore, from the FG follicles in this group, $86 \%$ of the oocytes retrieved were at the GV-intact stage. In contrast, $38 \%$ of the oocytes retrieved from the prepubertal animals were at the GV-intact stage, and only two GV-intact oocytes were retrieved from the older adult group.

The oocyte diameters of the FG, but not the SG, follicles from young adults were larger $(P<0.05)$ than those from the prepubertal group (Table 2). Oocyte retrieval from follicles of young adult animals was analyzed among the different culture conditions. The highest percentage of GV-intact oocytes, $70 \%$, were observed from the follicles cultured with $\mathrm{FSH}$, high-dose insulin, and LH. However, there was no significant difference in oocyte diameters among the different culture conditions (Table 3).

\section{Follicular steroids}

Since media steroid levels from the NG and SG follicles of prepubertal and older adult animals showed similar trends as those from young adults over the 5-week culture period (data not shown), only the data and analyses from the young adult group are presented in graphical form. For the NG follicles cultured within FSH and either low- or high-dose insulin, $\mathrm{E}_{2}$ levels remained at baseline throughout the culture period (Fig. 3A). For the SG (Fig. 3B) and FG (Fig. 3C) follicles cultured with $\mathrm{FSH}$ and high-dose insulin, $\mathrm{E}_{2}$ concentrations started rising by weeks $2-3$ and were higher $(P<0.05)$ by weeks 3-4 than those observed in the beginning of culture. $E_{2}$ levels for the SG follicles cultured with FSH and lowdose insulin stayed at baseline and were lower $(P<0.05)$ than those of the high-dose insulin-treated follicles at culture weeks 4 and 5 (Fig. 3B). There were no samples available for the FG follicles cultured with low-dose insulin. Similar patterns were also observed for A4 and $\mathrm{P}_{4}$ levels during the culture interval (e.g. SG follicles, Fig. 4A and $\mathrm{E}$ ).

In cultures of the $\mathrm{SG}$ follicles, levels of $\mathrm{A} 4$ (Fig. $4 \mathrm{~A}$ ), $\mathrm{E}_{2}$ (Fig. 4C), and $\mathrm{P}_{4}$ (Fig. 4E) did not increase between weeks 4 and 5 in the presence of FSH and high-dose insulin. However, the addition of $\mathrm{LH}$ at culture day 30 increased $(P<0.05)$ A4 (Fig. 4B), $E_{2}$ (Fig. 4D), and $P_{4}$ (Fig. 4F) production between pre-LH (week 4) and post-LH (week 5) exposure. In contrast, LH treatment had no effect on media steroid concentrations for the SG follicles cultured with low-dose insulin, which remained at baseline levels throughout the 5 weeks of culture (Fig. 4A-F).

In contrast to the SG follicles, the media levels of A4 (Fig. 5A), $E_{2}$ (Fig. 5B), and $\mathrm{P}_{4}$ (Fig. 5C) of the FG follicles increased $(P<0.05)$ between 4 and 5 weeks of culture in the presence of FSH and high-dose insulin. Moreover, LH supplementation at culture day $30 \mathrm{had}$ no effect on the pattern or levels of steroids during culture week 5 (Fig. 5A-C).

Figure 6 summarizes steroid levels produced by the SG follicles from monkeys of various ages during culture week 5 . Follicles from young adult animals displayed

Table 3 Characteristics of oocytes retrieved from young adult macaques follicles on day 40 of culture (34 h post recombinant human chorionic gonadotropin (rhCG) exposure), for different culture conditions.

\begin{tabular}{lccccc}
\hline & \multicolumn{3}{c}{ Number $(n)$ of } & \multicolumn{1}{c}{ Diameter $(\mu \mathrm{m})^{*}$} \\
\cline { 2 - 5 } Media type & Follicles harvested & Oocytes retrieved & Degenerate oocytes & GV-intact oocytes & GV-intact oocytes \\
\hline $0.05 \mu \mathrm{g} / \mathrm{ml}$ insulin & 8 & 2 & 1 & 1 & 95 \\
$0.05 \mu \mathrm{g} / \mathrm{ml}$ insulin $+\mathrm{LH}$ & 5 & 3 & 1 & 2 & $80 \pm 6$ \\
$5 \mu \mathrm{g} / \mathrm{ml}$ insulin & 6 & 5 & 3 & 2 & $92 \pm 7$ \\
$5 \mu \mathrm{g} / \mathrm{ml}$ insulin $+\mathrm{LH}$ & 16 & 10 & 3 & $95 \pm 5$ \\
\hline
\end{tabular}

*Values are the mean \pm S.E.M. 


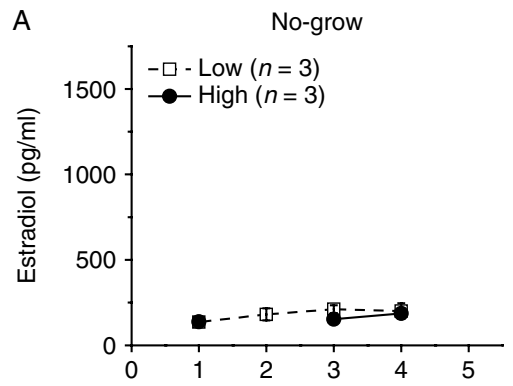

B
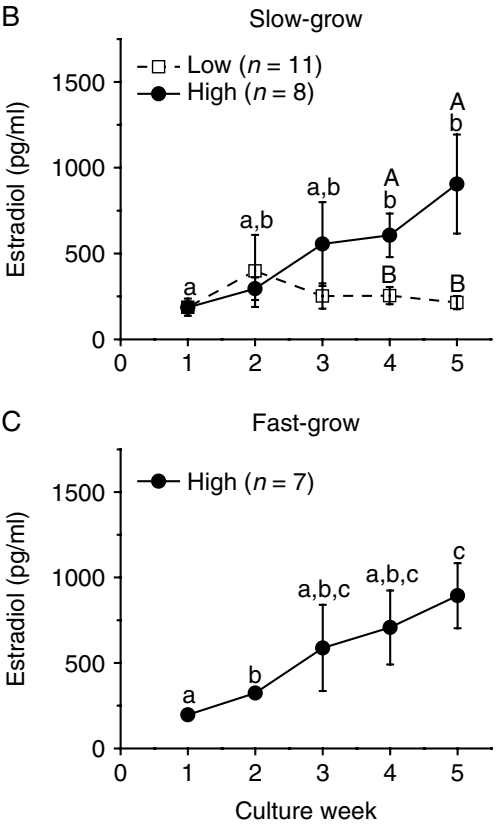

Figure 3 Insulin effect on estradiol production by macaque follicles in vitro. Estradiol levels for no-grow (panel A), slow-grow (panel B), and fast-grow (panel C) follicles from young adult animals $(n=3)$ during culture in media containing FSH and either low- or high-dose insulin, without LH supplementation at day 30. Significant differences over time (lowercase) or between the insulin dosage groups (uppercase) are indicated by different letters $(P<0.05)$. Data are presented as the mean \pm S.E.M.

higher $(P<0.05)$ A4 (Fig. 6A), $E_{2}$ (Fig. 6B), and $P_{4}$ (Fig. 6C) concentrations than those from prepubertal and older adult monkeys, when cultured with FSH and high-dose insulin. Follicles from prepubertal animals produced less $(P<0.05) \mathrm{E}_{2}$ (Fig. $\left.6 \mathrm{~B}\right)$ and more $(P<0.05)$ $\mathrm{P}_{4}$ (Fig. 6C) than follicles from older adults. While lacking samples from prepubertals and older adults, follicles from young adults cultured with FSH and highdose insulin produced higher $(P<0.05)$ amounts of ovarian steroids than those cultured with low-dose insulin (Fig. 6A-C).

\section{Anti-Müllerian hormone}

When follicles from young adult monkeys were cultured with FSH and high-dose insulin, the media $\mathrm{AMH}$ levels produced by the NG follicles did not change throughout the 4 weeks of culture (Fig. 7). In contrast, AMH levels of the SG and FG follicles peaked $(P<0.05)$ at week 2 and then declined $(P<0.05)$ to basal levels by week 3 (Fig. 7). Although diameters of the NG, SG, and FG follicles were not different on week 1 (data not shown), the levels of $\mathrm{AMH}$ produced by the SG and FG follicles were higher $(P<0.05)$ than those produced by the NG follicles. Also, AMH levels during week 2 were distinct $(P<0.05)$ among all the three follicle categories (Fig. 7). By week 3, all cultured follicles had basal levels of $\mathrm{AMH}$ that remained low even after LH treatment in week 5 (data not shown). Similar patterns were obtained for $\mathrm{AMH}$ concentrations throughout the culture period regardless of animal age and culture condition (data not shown).

\section{Vascular endothelial growth factor}

When follicles from young adult monkeys were cultured with FSH and high-dose insulin, the media VEGF levels produced by the NG follicles did not change throughout the 5 weeks of culture (Fig. 8). In contrast, VEGF levels of the SG and FG follicles increased markedly $(P<0.05)$
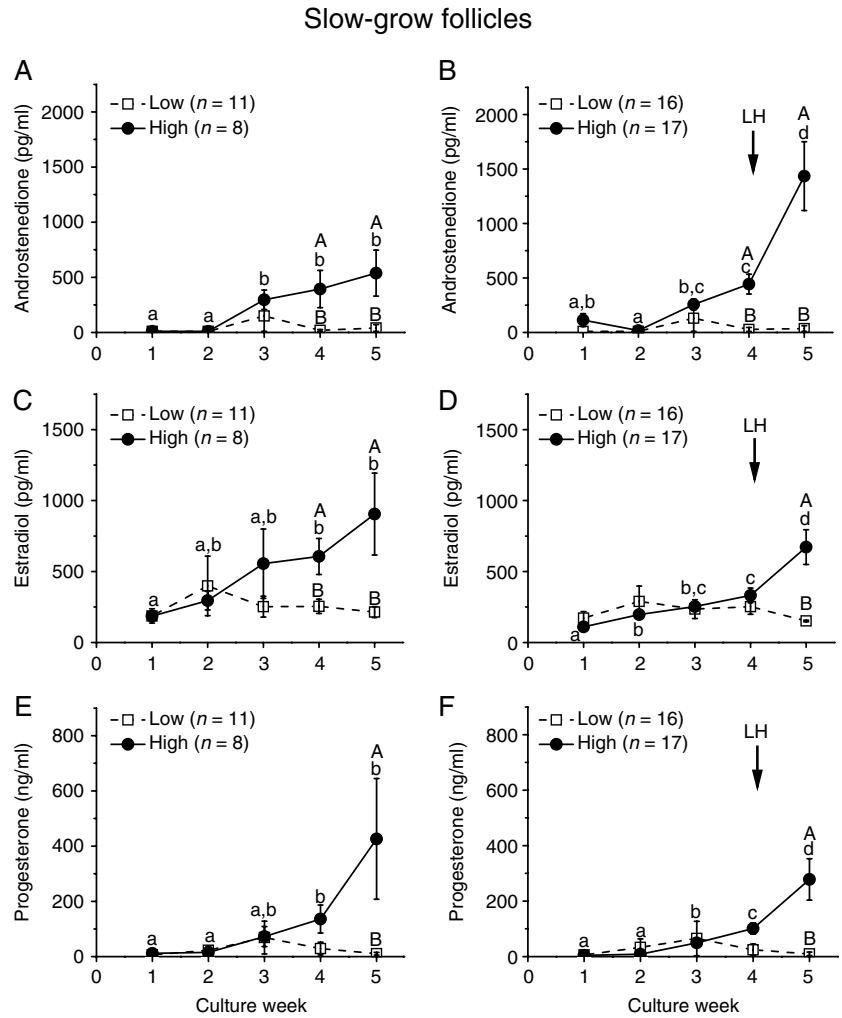

Figure 4 Insulin and LH effect on steroid production by slow-grow macaque follicles. Androstenedione (panels A and B), estradiol (panels $\mathrm{C}$ and $\mathrm{D}$ ), and progesterone (panels $\mathrm{E}$ and $\mathrm{F}$ ) levels for slow-grow follicles from young adult animals $(n=3)$ during culture in media containing FSH and either low- or high-dose insulin, without (panels A, $\mathrm{C}$ and $\mathrm{E}$ ) or with (panels $\mathrm{E}, \mathrm{D}$ and F) LH supplementation at day 30. Significant differences over time (lowercase) or between the insulin dosage groups (uppercase) are indicated by different letters $(P<0.05)$. Data are presented as the mean \pm s.E.M. 

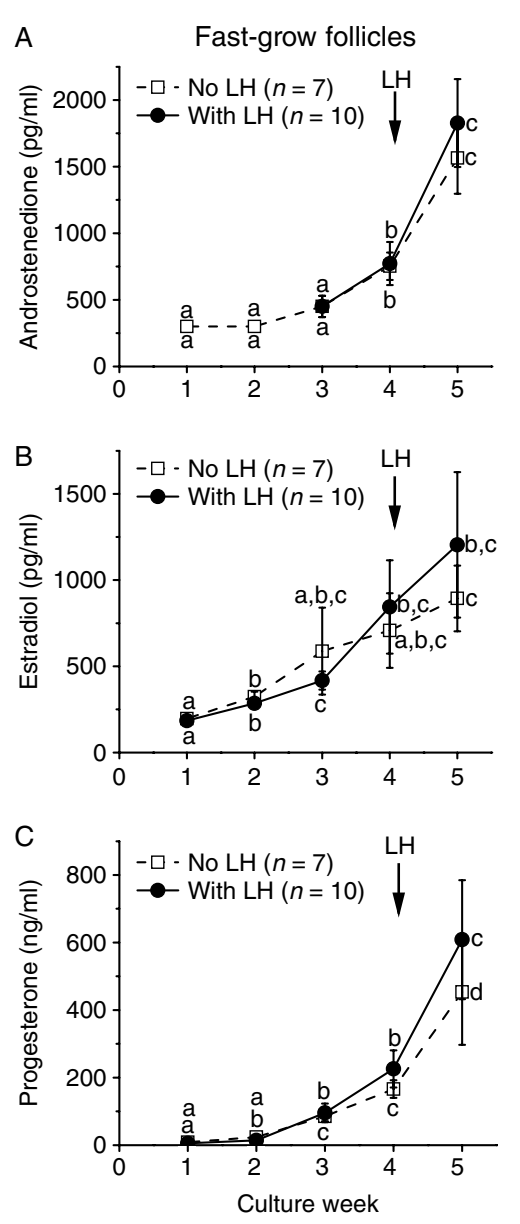

Figure $5 \mathrm{LH}$ effect on steroid production by fast-grow macaque follicles. Androstenedione (panel A), estradiol (panel B), and progesterone (panel C) levels for fast-grow follicles from young adult animals $(n=3)$ during culture in media containing FSH and high-dose insulin, without or with LH supplementation at day 30 . Significant differences over time are indicated by different letters $(P<0.05)$. Data are presented as the mean \pm s.E.M.

at weeks 4 and 5 (Fig. 8). Also, VEGF levels during weeks 4 and 5 were distinct $(P<0.05)$ among all the three follicle categories. By culture week 5 , the presence of $\mathrm{LH}$ did not alter VEGF concentrations for the SG or FG follicles (data not shown). Similar patterns were obtained for VEGF concentrations throughout 5 weeks of culture regardless of animal age and culture condition (data not shown).

\section{Discussion}

As described previously (Xu et al. 2009a), an alginatebased 3D culture system will support survival and growth of preantral (secondary) follicles from rhesus monkeys to the small antral stage. In this study, a greater percentage of secondary follicles from ovaries of prepubertal and young adult monkeys survived during the 5-week culture period than those from older adult animals. Our previous study demonstrated that follicles isolated during the follicular phase of the menstrual cycle had a higher survival rate than those from the luteal phase, but this may relate to differences in follicle size at onset of culture (Xu et al. 2009a). The mechanisms resulting in lower survival rate of follicles from older adult monkeys remain unclear, but it is not due to differences in follicle sizes at collection. Unknown factors responsible for the development of preantral follicles may protect them from programmed cell death (Orisaka et al. 2006). Preantral follicles from older animals may lack these apoptosis inhibiting factors and may not survive in culture. Alternatively, local factors inducing follicle atresia during early follicular development (Thompson et al. 2004) may increase during aging and result in decreased survival rate of preantral follicles from older animals. This feature of ovarian aging may be relevant to the clinical observation that the oocyte quality and fecundity, either spontaneous or assisted, decline by 30 years of age in premenopausal women (Gougeon 2005).

FSH is a critical hormone for survival of macaque secondary follicles (125-225 $\mu \mathrm{m}$ in diameter) in the alginate-based 3D culture system, regardless of animal age. Recently, Kreeger et al. (2005) examined the importance of FSH for survival, growth, and cell activity in murine secondary follicles cultured in a similar system. Notably, survival of multilayered follicles $(150-180 \mu \mathrm{m})$ was markedly improved by exposure to $\mathrm{FSH}$, in a dose-dependent manner, whereas survival of secondary follicles (100-130 $\mu \mathrm{m})$ was not altered by FSH exposure. The authors distinguished these groups of secondary follicles as FSH dependent versus FSH responsive, as the smaller follicles still exhibited dosedependent increases in growth, lactate production, and steroid secretion. Thus, the larger macaque secondary follicles appear FSH dependent comparable to those of the mouse, or perhaps even more so since some murine follicles survived in the absence of FSH. Likewise, FSH acts as a survival factor for human preantral follicles during ovarian tissue culture (Wright et al. 1999). These data are consistent with the evidence that FSH receptors are expressed in preantral follicles of various species, including primates (Gougeon 1996, Findlay \& Drummond 1999). However, an essential role for FSH in survival, as well as in growth, of preantral follicles in vitro is counter to evidence in vivo that human follicles survive and some grow to the small antral stage in conditions of low-to-nondetectable FSH levels, e.g. in infancy (Peters 1979) and in women during pregnancy (Khattab \& Jequier 1979), in disorders of hypogonadotropic hypogonadism (Goldenberg et al. 1976), and selective FSH (Rabin et al. 1972) or FSH receptor (Aittomäki et al. 1996) defects. Perhaps, the ovarian milieu/tissue in vivo, in the absence or presence of gonadotropins, can promote survival of small growing follicles. 

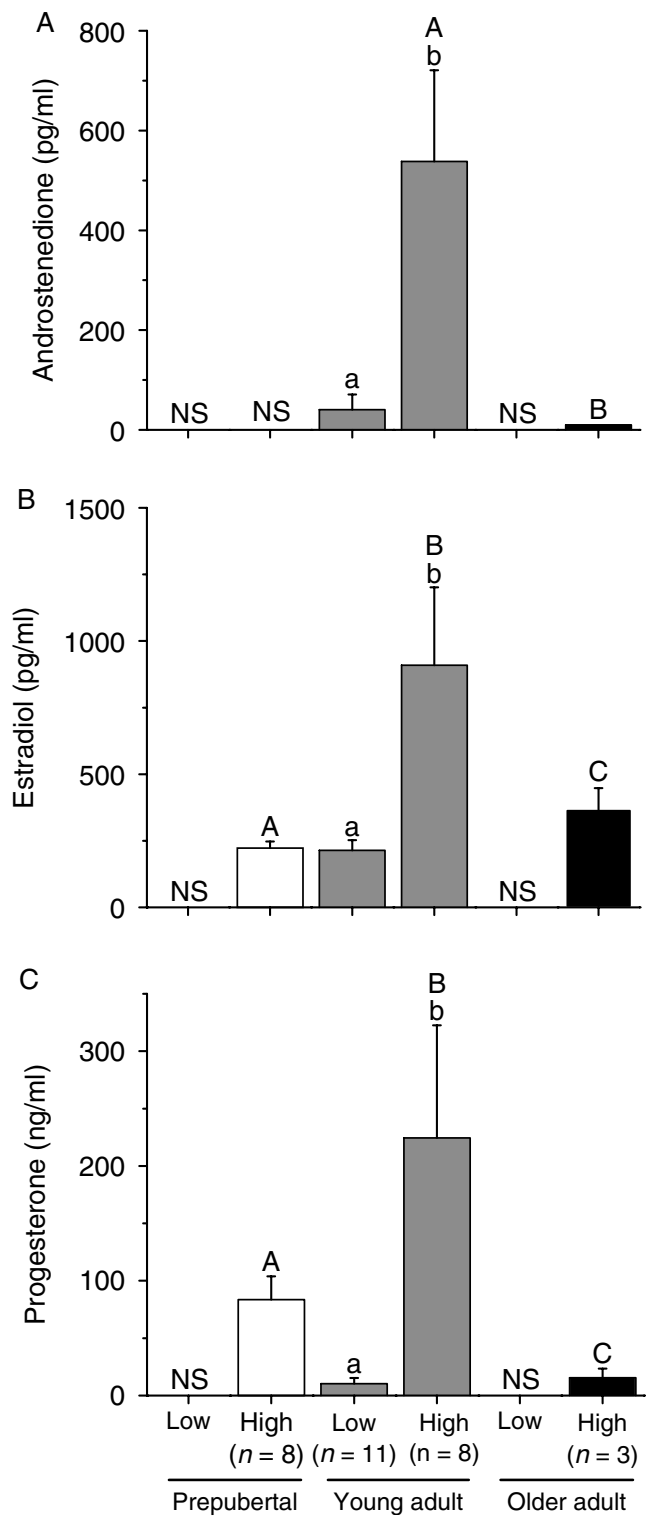

Figure 6 Androstenedione (panel A), estradiol (panel B), and progesterone (panel C) levels for slow-grow macaque follicles from prepubertal $(n=3)$, young $(n=3)$, and older $(n=3)$ adult animals during culture in media containing FSH and either low- or high-dose insulin, without LH supplementation at day 30. Significant differences within (lowercase) or between the age groups (uppercase) are indicated by different letters $(P<0.05)$. Data are presented as the mean \pm S.E.M. NS, no sample available.

The surviving macaque secondary follicles could be categorized into three groups (NG, SG, and FG) according to their growth rate, i.e. diameters achieved by culture day 40 . This phenomenon was not documented in previous studies on in vitro follicle growth. During similar 3D culture, mouse secondary follicles grew from $<200$ to $400 \mu \mathrm{m}$ diameter, reached the antral stage within 8 days, and provided mature oocytes for IVF (Spears et al. 1998, Xu et al. 2006). Any diversity in growth rate among murine follicles may be less evident due to the shorter culture period and smaller increase (doubling) in follicle diameter. In initial studies on human secondary follicles (Xu et al. 2009b), the differences in follicle growth rate may not have been obvious due to small sample size. However, it was observed that $75 \%$ of the surviving follicles developed visible antrum, while others remained at multilayered stage through 30 days of culture. The current data suggest that the population of small secondary follicles in the primate ovary at the early follicular phase of the cycle is heterogeneous in their capacity to grow in an $\mathrm{FSH}$ replete milieu. Their growth rate may depend upon their ability to recognize or respond to $\mathrm{FSH}$ (Kreeger et al. 2005) or other hormones (e.g. insulin, see below), or to synthesize and respond to other local factors that modulate follicular growth. For example, the heterogeneity of the small preantral follicle pool is supported by the proportion of size-matched preantral follicles in the marmoset ovary that immunolocalized $\mathrm{AMH}$ (Thomas et al. 2007).

In addition, the proportion of follicles in the three groups and their growth rates differed as a function of animal age. The NG follicles were observed and exhibited minimal growth in all the three age groups. However, the SG follicles from young adult animals grew faster and reached a larger size than those from prepubertal monkeys. Moreover, the FG follicles were only observed in young adult group. Also during culture with $\mathrm{FSH}$, follicles from young adult animals yielded more healthy GV-intact oocytes with larger diameters than those from prepubertals. The latter observation is consistent with the report that FSH treatment of postmenarcheal rhesus monkeys yielded more mature oocytes with higher development potential during IVF than treatment of juveniles (Yang et al. 2009). In different species, including primates, FSH receptor expression increases during early folliculogenesis, and the receptors remain on granulosa cells of healthy follicles until they become atretic or luteinize (Findlay \& Drummond 1999). Again, it is possible that compared with follicles from young adults, the FSH receptor expression and signaling pathway were not fully developed in follicles from prepubertal ovaries. Likewise, the FG follicles were not obtained from older adult culture group, and few healthy GV-intact oocytes retrieved may relate to decreased FSH receptor expression and signaling through aging.

During encapsulated 3D culture, the addition of $\mathrm{LH}$ at day 30 (after antrum formation) had no effect on the survival and further growth of primate follicles. This is consistent with in vivo evidence that antral follicular development can occur in the presence of minimal (hypogonadal) levels of LH in monkeys (Zelinski-Wooten et al. 1995) and women (Schoot et al. 1994, Kumar et al. 1997). However, LH administration markedly increased ovarian steroid production in the SG follicles. The increased androgen and estrogen levels are consistent 


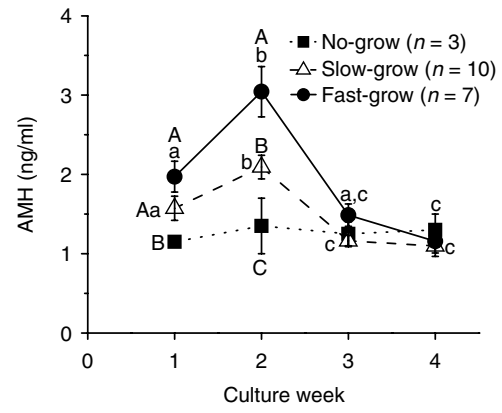

Figure $7 \mathrm{AMH}$ concentrations for no-grow, slow-grow, and fast-grow follicles from young adult macaques $(n=3)$ during culture in media containing FSH and high-dose insulin, without $\mathrm{LH}$ supplementation at day 30. Significant differences over time (lowercase) or among the follicle categories (uppercase) are indicated by different letters $(P<0.05)$. Data are presented as the mean \pm S.E.M.

with the 2-cell, 2-gonadotropin model wherein $\mathrm{LH}$ receptor signaling promotes $\mathrm{A} 4$ production by theca cells, which allows steroidogenic maturation of the follicles by providing $\mathrm{A} 4$ as substrate for $\mathrm{E}_{2}$ production in the granulosa cells (McNatty et al. 1980). Elevated $P_{4}$ levels in the culture media may represent substrate for A4 and $E_{2}$ production or be a sign of luteinization in follicles with degenerate oocytes (Fauser \& Van Heusden 1997). In contrast, an LH effect on steroidogenesis was not observed in the FG follicles. This may be due to the high steroid production prior to the LH addition, which prevented further stimulation. In our previous study, continuous $\mathrm{LH}$ exposure during follicle culture promoted $\mathrm{E}_{2}$, but not $\mathrm{A} 4$ and $\mathrm{P}_{4}$, production (Xu et al. 2009a). This may result from the desensitizing of $\mathrm{LH}$ receptors by continuous $\mathrm{LH}$ exposure or by not distinguishing SG from FG follicles. Our current data also indicate that $\mathrm{LH}$ had no effect on $\mathrm{AMH}$ and VEGF production during follicle culture. Since AMH levels declined to baseline at antrum formation, this transient follicular activity preceded $\mathrm{LH}$ exposure at day 30 of

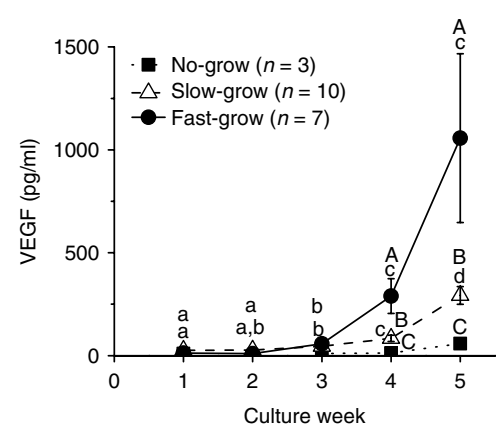

Figure 8 VEGF concentrations for no-grow, slow-grow, and fast-grow follicles from young adult macaques $(n=3)$ during culture in media containing FSH and high-dose insulin, without LH supplementation at day 30. Significant differences over time (lowercase) or among the follicle categories (uppercase) are indicated by different letters $(P<0.05)$. Data are presented as the mean \pm S.E.M. culture. In contrast, VEGF production, at least by granulosa cells, appears to reach the capacity in the large preovulatory follicle and is regulated by surge levels of gonadotropin (Ravindranath et al. 1992, Christenson \& Stouffer 1997). This study suggests that low nonsurge levels of $\mathrm{LH}$ do not promote VEGF production by small antral follicles.

Insulin may regulate various intracellular processes in the follicle such as amino acid transport, lipid metabolism, gene transcription, and protein synthesis (Louhio et al. 2000). Insulin receptors are expressed in mammalian ovaries; its mRNA and protein are located in theca, granulosa, and stromal cells of antral follicles in women (el-Roeiy et al. 1993, Samoto et al. 1993). Insulin receptor gene expression was also detected in in vitro matured oocytes from small antral follicles in monkeys (Zheng et al. 2007). In this study, it was observed that insulin had no effect on follicle survival, but at the higher dose, it promoted further growth of the FG follicles from young adult animals after 3 weeks of culture. This was the time when the follicles reached $\geq 400 \mu \mathrm{m}$ in diameter, and the antral cavity started to form. Also, more healthy GV-intact oocytes were retrieved and their sizes tended to be larger in the follicles cultured with high-dose insulin. Our results support previous reports that insulin had a positive effect on ovarian folliculogenesis and oocyte maturation, including human follicular growth in vitro (Wright et al. 1999). However, an in vitro study on murine cumulus-oocyte complexes (COC) indicated that insulin can have profound detrimental effects on oocyte developmental competence (Eppig et al. 1998). Insulin or FSH may also modulate local insulin-like growth factor (IGF) activity, which was suggested to improve the viability of cultured follicles in primates (Louhio et al. 2000). Further studies on the effects of insulin and IGFs, both of which are present at appreciable levels in follicular fluid of primate antral follicles (Brogan et al. 2010), on follicle growth and oocyte quality are warranted in primates.

Follicle growth rate correlated with steroid hormone production in vitro. Unlike NG follicles, the SG and FG follicles produced appreciable levels of $A 4, E_{2}$, and $P_{4}$ within 5 weeks of culture in the encapsulated 3D system. Media steroid levels first increased when the antrum appeared as similarly reported in mouse follicles in culture (West-Farrell et al. 2009). Since A4 production is generally limited to the theca layer (Tamura et al. 1992), this encapsulated 3D system may support theca cell development or function in macaque, as well as in mouse (Xu et al. 2006), follicles. Interestingly, this steroidogenic process was observed in follicles cultured with high-dose, but not low-dose, insulin. In mammals, insulin has been shown to promote theca and granulosa cell steroidogenesis (Barbieri et al. 1984, Erickson et al. 1990, Langhout et al. 1991). Thus, insulin/ IGFs may be an important regulator of primate thecagranulosa differentiation and steroidogenesis in vitro. 
Despite exposure to the same dose of insulin, cultured follicles from prepubertal and older adult animals displayed lower ovarian steroid levels in the media. This may be due to lower FSH sensitivity of the follicles as described above (Davoren \& Hsueh 1984). Follicle growth may be delayed, and follicle function may be impaired in prepubertal and older adults if insulinenhanced FSH-stimulated steroidogenesis is lacking.

This study provided the first quantitative assessment of $\mathrm{AMH}$ production by isolated primate preantral follicles. AMH production by early preantral follicles correlated positively with growth rate, i.e. the FG follicles produced greater levels than the SG follicles, with lesser production by the NG follicles. AMH production displayed a transient increase at culture week 2 and decreased by antrum formation. Previous studies localized AMH mRNA or protein to granulosa cells of preantral and small antral follicles, which diminished in the subsequent stages of follicle development; expression was also absent in atretic follicles and the corpus luteum (Durlinger et al. 2002, Weenen et al. 2004, Thomas et al. 2007). Thus, early AMH production may be a potential marker for predicting further development of cohorts of preantral follicles with different growth rates during culture, prior to any differences in follicle diameter and steroidogenic capacity. Efforts continue attempting to elucidate the role of AMH on follicular function (Visser et al. 2007, La Marca et al. 2009). The addition of AMH into cultures of human or rat ovarian cortical strips, improved the recruitment, survival, and growth of primordial follicles (McGee et al. 2001, Schmidt et al. 2005) suggesting a stimulatory role of AMH on very early follicular development. However, a direct role for AMH on primary or secondary follicle function has yet to be demonstrated. AMH may not only be a marker, but also an important local factor regulating follicle growth in encapsulated 3D culture system.

This study also demonstrated, for the first time, that small antral follicles in primates produce VEGF. Media VEGF levels increased at culture week 3 during antrum formation, correlated with growth rate, and were greatest in the FG follicles. The pattern is consistent with previous in vivo studies that VEGF mRNA (Ravindranath et al. 1992) and protein (Yamamoto et al. 1997) were expressed in the theca cells of antral follicles and granulosa cells nearest the oocyte in the preovulatory follicle of primates, but not in the granulosa cells of primordial and preantral follicles. VEGF likely plays an angiogenic role during antrum development when the theca layer acquires a vascular sheath to provide an increased supply of gonadotropins, growth factors, oxygen, and steroid precursors to the growing follicle (Stouffer et al. 2001). Increased VEGF production by the SG and FG follicles in encapsulated 3D culture may indicate achievement of a size and maturation state in the follicle, at the antral stage, that requires vascularization to achieve further development in vivo with additional substrates and release of hormones. Besides an angiogenic action, VEGF may also be a cytoprotective factor in the extravascular granulosa cell compartment. Co-expression of VEGF and its receptor reportedly protects bovine granulosa cells from apoptotic cell death and follicle atresia (Greenaway et al. 2004). VEGF may also promote nuclear and cytoplasmic maturation of bovine oocytes in vitro (Luo et al. 2002). Given that increasing follicle diameter correlated positively with increased VEGF production, VEGF may play a role during follicle development and/or be a marker of follicle quality in vitro.

In addition to appreciable number of degenerate oocytes, the healthy oocytes within the SG or FG follicles after 40 days of culture did not respond to rhCG treatment with reinitiation of meiotic maturation and remained at the GV-intact stage. In order to acquire meiotic competence, the oocytes need to grow and reach a stage at which they are able to activate cyclindependent protein kinase (CDC2) and MAP kinases (Miyano \& Manabe 2007). Chromatin configurations and meiotic competence of oocytes are related to follicular diameter as reported in rodents (Erickson \& Sorensen 1974, Iwamatsu \& Yanagimachi 1975) and nonstimulated rhesus monkeys. Limited data from rhesus monkeys suggest that $56 \%$ of oocytes from large antral follicles ( $>1000 \mu \mathrm{m}$ in diameter) completed maturation, whereas few $(9 \%)$ oocytes from small antral follicles (200-450 $\mu \mathrm{m}$ in diameter) were competent to mature in vitro (Schramm et al. 1993). The current culture systems need to be improved to promote further follicle growth, as well as the health and further growth of the oocytes to reach the size of those that mature in vivo, which is over $100 \mu \mathrm{m}$ in diameter in macaque (Buse et al. 2008). Gap junctional communication within the COC matrix is likely critical for oocyte metabolism, maturation, and meiotic progression in primates, as in other species (Kimura et al. 2007). However, the cumulus-oocyte communication could be compromised by the current milieu and extended interval of encapsulated 3D culture, such that oocytes cannot achieve the competence to undergo meiotic or cytoplasmic maturation. Future studies on the characteristics of COC of antral follicles derived from secondary follicles during encapsulated 3D culture are warranted.

Thus, advances in an encapsulated 3D culture of nonhuman primate secondary follicles to the small antral stage provide a model to study indices of follicle development with individual follicles. This model offers an opportunity to characterize the endocrine and paracrine function of primate follicles that influence follicle growth and oocyte maturation, with relevance to translational efforts to grow human follicles in vitro. By achieving the goal of producing competent oocytes, in vitro follicle maturation may offer a means to enhance fertility preservation options in women. 


\section{Materials and Methods}

\section{Animals and ovary collection}

The general care and housing of rhesus macaques were provided by the Division of Animal Resources at the Oregon National Primate Research Center (ONPRC). Animals, different from those used in our previous study (Xu et al. 2009a), were pair caged in a temperature-controlled $\left(22^{\circ} \mathrm{C}\right)$ light-regulated $12 \mathrm{~h}$ light:12 $\mathrm{h}$ darkness room. Diet consisted of Purina monkey chow (Ralston-Purina, Richmond, IN, USA) provided twice a day, supplemented with fresh fruit or vegetables once a day and water made available ad libitum. Animals were treated according to the National Institutes of Health Guide for the Care and Use of Laboratory Animals and protocols approved by the ONPRC Institutional Animal Care and Use Committee.

Young adult female rhesus macaques $(n=3 ; 4-11$ years of age) exhibiting regular menstrual cycles of $\sim 28$ days were evaluated daily for menstruation with the first day of menses being termed day 1 of the cycle. Ovariectomies were conducted on anesthetized monkeys by laparoscopy at early follicular phase, days 1-3 of the cycle, as described previously (Duffy \& Stouffer 2002). Ovaries were also obtained from prepubertal ( $n=3,1-3$ years of age) and regular cycling, older adult $(n=3,13-16$ years of age) monkeys. Ovaries were immediately transferred into HEPES-buffered holding media (CooperSurgical, Inc., Trumbull, CT, USA) supplemented with $0.2 \%(\mathrm{v} / \mathrm{v})$ human serum protein supplement (SPS; CooperSurgical, Inc.) and $10 \mu \mathrm{g} / \mathrm{ml}$ gentamicin (Sigma-Aldrich).

\section{Follicle isolation, encapsulation, and culture}

Follicle isolation and encapsulation were carried out as described previously (Xu et al. 2009a). Briefly, the ovarian cortex was cut into $2 \times 2 \times 1 \mathrm{~mm}$ cortical strips and incubated in $6 \mathrm{ml}$ holding media (as described above) containing $275 \mathrm{U} / \mathrm{ml}$ collagenase type I and $585 \mathrm{U} / \mathrm{ml}$ DNase I (Worthington Biochemical Corp., Lakewood, NJ, USA) at $37^{\circ} \mathrm{C}$ for $30 \mathrm{~min}$. Follicles were mechanically isolated in the holding media (as described above) using 31-gauge needles, and the secondary follicles with diameters of 125-225 $\mu \mathrm{m}$ that displayed the following characteristics were selected for encapsulation: i) no clear antral cavity, ii) an intact basement membrane with attached stroma, and iii) a visible oocyte that was round and centrally located within the follicle.

Follicles were transferred individually into $5 \mu \mathrm{l} 0.25 \%(\mathrm{w} / \mathrm{v})$ sterile sodium alginate (FMC BioPolymers, Philadelphia, PA, USA) in PBS (137 mM NaCl, $10 \mathrm{M}$ phosphate, $2.7 \mathrm{mM} \mathrm{KCl}$, Invitrogen), and the droplets were crosslinked in $50 \mathrm{mM} \mathrm{CaCl}_{2}$ and $140 \mathrm{mM} \mathrm{NaCl}$ solution for $2 \mathrm{~min}$. Each alginate-encapsulated follicle was then transferred into individual wells of 48-well plates containing $300 \mu \mathrm{l} \alpha$ minimum essential medium (Invitrogen) supplemented with $0.3 \%$ SPS, $1 \mathrm{mg} / \mathrm{ml}$ bovine fetuin, $5 \mu \mathrm{g} / \mathrm{ml}$ transferrin, and $5 \mathrm{ng} / \mathrm{ml}$ sodium selenite (Sigma-Aldrich).

Encapsulated follicles were cultured at $37^{\circ} \mathrm{C}$ in $5 \%(\mathrm{v} / \mathrm{v}) \mathrm{CO}_{2}$ in air atmosphere in the absence or presence of $500 \mathrm{mlU} / \mathrm{ml}$ rhFSH (NV Organon, Oss, The Netherlands) and 0.05 or $5 \mu \mathrm{g} / \mathrm{ml}$ insulin (low or high dose, Sigma-Aldrich) for 30 days. Thereafter, half of the follicles in each culture condition received $10 \mathrm{mIU} / \mathrm{ml}$ rhLH (Ares-Serono, Inc., Randolph, MA, USA) in the media from days 30-40. Follicles that reached the antral stage were treated with $100 \mathrm{ng} / \mathrm{ml}$ rhCG (Merck Serono) for $34 \mathrm{~h}$. Oocytes were then retrieved to determine competence for meiotic maturation. Half of the culture media $(150 \mu \mathrm{l})$ was collected and replaced every other day and stored at $-20{ }^{\circ} \mathrm{C}$. The three media samples from each culture week were assigned to ovarian steroids, AMH, and VEGF assays.

\section{Follicle survival, growth, and oocyte maturation}

Follicle survival, diameter, and antrum formation were assessed weekly using an Olympus CK40 inverted microscope and an Olympus DP11 digital camera (Olympus Imaging America, Inc., Center Valley, PA, USA) as described previously (Xu et al. 2009a). Follicles were measured from the outer layer of cells, which included a measurement at the widest diameter of the follicle and a second measurement perpendicular to the first. The mean of these values was then calculated and reported as the follicle diameter. Any clumps of presumptive discontinuous stromal cells (Fig. 1B-D) were not included. Follicles were considered undergoing atresia if the oocyte was dark or not surrounded by a layer of granulosa cells, the granulosa cells became dark and fragmented, or the diameter of the follicle decreased. Follicle photographs were imported into ImageJ 1.42 software (National Institutes of Health, Bethesda, MD, USA), and the diameter of each follicle was measured. Retrieved oocytes were also photographed, and oocyte diameters were measured using the same camera and software as described above.

\section{Ovarian steroids, $A M H$, and VEGF assays}

Media collected during culture weeks 1-5 were analyzed for $E_{2}$ and $\mathrm{P}_{4}$ concentrations by the Endocrine Technology Support Core at the ONPRC using an Immulite 2000, a chemiluminescence-based automatic clinical platform (Siemens Healthcare Diagnostics, Deerfield, IL, USA), according to the manufacturers' protocol as reported previously (Xu et al. 2009a). Media A4 levels were measured by RIA using a DSL3800 kit (Diagnostic Systems Laboratories, Inc., Webster, TX, USA). The assay was validated for parallelism with blank culture media containing a known concentration of A4, and with media used in culture with monkey follicles. The sensitivity of the assay was $0.1 \mathrm{ng} / \mathrm{ml}$ for $50 \mu \mathrm{l}$ sample. The standard curve of the assay ranged $0.1-10 \mathrm{ng} / \mathrm{ml}$. The coefficient of variation (CV) values for standard points (in duplicate) at $0,0.1,0.3,1.0,3.0$, and $10.0 \mathrm{ng} / \mathrm{ml}$ in the assays were $0.7,0.5,1.4,1.8,0.1$, and $1.5 \%$ respectively.

Media collected during culture weeks 1-5 were analyzed for AMH concentrations by ELISA using a DSL-10-14400 kit (Diagnostic Systems Laboratories, Inc.) based on the manufacturers' instructions (Fréour et al. 2007). The assay was validated for parallelism with blank culture media containing a known concentration of $\mathrm{AMH}$, and with media used in culture with monkey follicles. The sensitivity of the assay was $0.05 \mathrm{ng} / \mathrm{ml}$ for $20 \mu \mathrm{l}$ sample. The standard curve of the assay ranged $0.05-14 \mathrm{ng} / \mathrm{ml}$. The CV values for standard points (in duplicate) at $0,0.05,0.1,0.26,2.0,7.8$, and $14.0 \mathrm{ng} / \mathrm{ml}$ in the assays were 
1.6, 5.0, 1.5, 2.8, 1.7, 3.6, and 1.9\% respectively. Extensive validation experiments revealed that fetuin in the culture media crossreacted with the AMH antibody. Therefore, levels assayed in media containing fetuin without cultured follicles were subtracted from $\mathrm{AMH}$ levels in media samples from follicle culture.

Media from culture weeks 1-5 were also assayed for VEGF concentrations using a Human VEGF Quantikine ELISA Kit (R\&D Systems, Minneapolis, MN, USA) as validated previously for macaque serum and culture media (Christenson \& Stouffer 1997).

\section{Statistical analysis}

Statistical significance was analyzed by SigmaPlot 11 software (SPSS, Inc., Chicago, IL, USA) using a two-way ANOVA with repeated measures or one-way ANOVA followed by the Student Newman-Keuls post hoc test for single time points. Differences were considered significant at $P<0.05$, and values are presented as mean \pm S.E.M.

\section{Declaration of interest}

The authors declare that there is no conflict of interest that could be perceived as prejudicing the impartiality of the research reported.

\section{Funding}

This work was supported by the National Institutes of Health (grant number NIH UL1 RR024926 (R01-HD058294, PL1-EB008542), U54-HD18185, NCRR-RR00163, HD07133, D43TW000668-Fogarty).

\section{Acknowledgements}

We are grateful to the members of the Division of Animal Resources, the Endocrine Technology Support Core, the Assisted Reproductive Technology/Embryonic Stem Cell Support Core, and the Colony Demographics and Informatics Unit at the ONPRC, as well as to Drs Min Xu, Lonnie Shea, and Teresa Woodruff at the Northwestern University, for their valuable expertise and technical assistance. We thank $\mathrm{N} \vee$ Organon for providing the $\mathrm{rhFSH}$.

\section{References}

Aittomäki K, Herva R, Stenman UH, Juntunen K, Ylöstalo P, Hovatta O \& de la Chapelle A 1996 Clinical features of primary ovarian failure caused by a point mutation in the follicle stimulating hormone receptor gene. Journal of Clinical Endocrinology and Metabolism 81 3722-3726. (doi:10.1210/jc.81.10.3722)

Albertini DF, Combelles CM, Benecchi E \& Carabatsos MJ 2001 Cellular basis for paracrine regulation of ovarian follicle development. Reproduction 121 647-653. (doi:10.1530/rep.0.1210647)

Barbieri RL, Makris A \& Ryan KJ 1984 Insulin stimulates androgen accumulation in incubations of human ovarian stroma and theca. Obstetrics and Gynecology 64 73S-80S.
Brogan RS, Mix S, Puttabyatappa M, Vandevoort CA \& Chaffin CL 2010 Expression of the insulin-like growth factor and insulin systems in the luteinizing macaque ovarian follicle. Fertility and Sterility 93 1421-1429. (doi:10.1016/j.fertnstert.2008.12.096)

Bruno JB, Celestino JJ, Lima-Verde IB, Lima LF, Matos MH, Araújo VR, Saraiva MV, Martins FS, Name KP, Campello CC et al. 2009 Expression of vascular endothelial growth factor (VEGF) receptor in goat ovaries and improvement of in vitro caprine preantral follicle survival and growth with VEGF. Reproduction, Fertility, and Development 21 679-687. (doi:10.1071/RD08181)

Buse E, Zöller M \& Van Esch E 2008 The macaque ovary, with special reference to the cynomolgus macaque (Macaca fascicularis). Toxicologic Pathology 36 24S-66S. (doi:10.1177/0192623308327407)

Carlsson IB, Scott JE, Visser JA, Ritvos O, Themmen AP \& Hovatta O 2006 Anti-Müllerian hormone inhibits initiation of growth of human primordial ovarian follicles in vitro. Human Reproduction 21 2223-2227. (doi:10.1093/humrep/del165)

Chand AL, Harrison CA \& Shelling AN 2010 Inhibin and premature ovarian failure. Human Reproduction Update 16 39-50. (doi:10.1093/humupd/ dmp031)

Christenson LK \& Stouffer RL 1997 Follicle-stimulating hormone and luteinizing hormone/chorionic gonadotropin stimulation of vascular endothelial growth factor production by macaque granulosa cells from pre- and periovulatory follicles. Journal of Clinical Endocrinology and Metabolism 82 2135-2142. (doi:10.1210/jc.82.7.2135)

Cortvrindt R, Hu Y \& Smitz J 1998 Recombinant luteinizing hormone as a survival and differentiation factor increases oocyte maturation in recombinant follicle stimulating hormone-supplemented mouse preantral follicle culture. Human Reproduction 13 1292-1302. (doi:10.1093/humrep/13.5.1292)

Davoren JB \& Hsueh AJ 1984 Insulin enhances FSH-stimulated steroidogenesis by cultured rat granulosa cells. Molecular and Cellular Endocrinology 35 97-105. (doi:10.1016/0303-7207(84)90005-4)

Drummond AE 2006 The role of steroids in follicular growth. Reproductive Biology and Endocrinology 4 16. (doi:10.1186/1477-7827-4-16)

Duffy DM \& Stouffer RL 2002 Follicular administration of a cyclooxygenase inhibitor can prevent oocyte release without alteration of normal luteal function in rhesus monkeys. Human Reproduction 17 2825-2831. (doi:10.1093/humrep/17.11.2825)

Durlinger AL, Visser JA \& Themmen AP 2002 Regulation of ovarian function: the role of anti-Müllerian hormone. Reproduction $\mathbf{1 2 4}$ 601-609. (doi:10.1530/rep.0.1240601)

Eppig JJ 2001 Oocyte control of ovarian follicular development and function in mammals. Reproduction 122 829-838. (doi:10.1530/rep.0. 1220829)

Eppig JJ, O'Brien MJ, Pendola FL \& Watanabe S 1998 Factors affecting the developmental competence of mouse oocytes grown in vitro: folliclestimulating hormone and insulin. Biology of Reproduction 59 1445-1453. (doi:10.1095/biolreprod59.6.1445)

Erickson GF \& Sorensen RA 1974 In vitro maturation of mouse oocytes isolated from late, middle, and pre-antral graafian follicles. Journal of Experimental Zoology 190 123-127. (doi:10.1002/jez.1401900112)

Erickson GF, Magoffin DA, Cragun JR \& Chang RJ 1990 The effects of insulin and insulin-like growth factors-I and -II on estradiol production by granulosa cells of polycystic ovaries. Journal of Clinical Endocrinology and Metabolism 70 894-902. (doi:10.1210/jcem-70-4-894)

Ewens KG, Stewart DR, Ankener W, Urbanek M, McAllister JM, Chen C, Baig KM, Parker SC, Margulies EH, Legro RS et al. 2010 Family-based analysis of candidate genes for polycystic ovary syndrome. Journal of Clinical Endocrinology and Metabolism 95 2306-2315. (doi:10.1210/ jc.2009-2703)

Fauser BC \& Van Heusden AM 1997 Manipulation of human ovarian function: physiological concepts and clinical consequences. Endocrine Reviews 18 71-106. (doi:10.1210/er.18.1.71)

Findlay JK \& Drummond AE 1999 Regulation of the FSH receptor in the ovary. Trends in Endocrinology and Metabolism 10 183-188. (doi:10. 1016/S1043-2760(98)00144-1)

Fréour T, Mirallié S, Bach-Ngohou K, Denis M, Barrière P \& Masson D 2007 Measurement of serum anti-Müllerian hormone by Beckman Coulter ELISA and DSL ELISA: comparison and relevance in assisted reproduction technology (ART). Clinica Chimica Acta 375 162-164. (doi:10.1016/j.cca.2006.06.013) 
Goldenberg RL, Powell RD, Rosen SW, Marshall JR \& Ross GT 1976 Ovarian morphology in women with anosmia and hypogonadotropic hypogonadism. American Journal of Obstetrics and Gynecology 126 91-94.

Gougeon A 1996 Regulation of ovarian follicular development in primates: facts and hypotheses. Endocrine Reviews 17 121-155. (doi:10.1210/ edrv-17-2-121)

Gougeon A 1998 Ovarian follicular growth in humans: ovarian ageing and population of growing follicles. Maturitas 30 137-142. (doi:10.1016/ S0378-5122(98)00069-3)

Gougeon A 2005 The biological aspects of risks of infertility due to age: the female side. Revue d'Épidémiologie et de Santé Publique 53 2S37-2S45. (doi:10.1016/S0398-7620(05)84766-2)

Greenaway J, Connor K, Pedersen HG, Coomber BL, LaMarre J \& Petrik J 2004 Vascular endothelial growth factor and its receptor, Flk-1/KDR, are cytoprotective in the extravascular compartment of the ovarian follicle. Endocrinology 145 2896-2905. (doi:10.1210/en.2003-1620)

Hazzard TM \& Stouffer RL 2000 Angiogenesis in ovarian follicular and luteal development. Baillière's Best Practice \& Research. Clinical Obstetrics \& Gynaecology 14 883-900. (doi:10.1053/beog.2000.0133)

Iwamatsu T \& Yanagimachi R 1975 Maturation in vitro of ovarian oocytes of prepubertal and adult hamsters. Journal of Reproduction and Fertility $\mathbf{4 5}$ 83-90. (doi:10.1530/jrf.0.0450083)

Khattab TY \& Jequier AM 1979 Serum follicle stimulating hormone levels in human pregnancy. British Journal of Obstetrics and Gynaecology 86 354-363. (doi:10.1111/j.1471-0528.1979.tb10610.x)

Kimura N, Hoshino Y, Totsukawa K \& Sato E 2007 Cellular and molecular events during oocyte maturation in mammals: molecules of cumulusoocyte complex matrix and signalling pathways regulating meiotic progression. Society of Reproduction and Fertility Supplement 63 327-342.

Kreeger PK, Fernandes NN, Woodruff TK \& Shea LD 2005 Regulation of mouse follicle development by follicle-stimulating hormone in a threedimensional in vitro culture system is dependent on follicle stage and dose. Biology of Reproduction 73 942-950. (doi:10.1095/biolreprod. 105.042390)

Kumar TR, Wang Y, Lu N \& Matzuk MM 1997 Follicle stimulating hormone is required for ovarian follicle maturation but not male fertility. Nature Genetics 15 201-204. (doi:10.1038/ng0297-201)

La Marca A, Broekmans FJ, Volpe A, Fauser BC, Macklon NS \& ESHRE Special Interest Group for Reproductive Endocrinology - AMH Round Table 2009 Anti-Müllerian hormone (AMH): what do we still need to know? Human Reproduction 24 2264-2275. (doi:10.1093/humrep/ dep210)

Langhout DJ, Spicer LJ \& Geisert RD 1991 Development of a culture system for bovine granulosa cells: effects of growth hormone, estradiol, and gonadotropins on cell proliferation, steroidogenesis, and protein synthesis. Journal of Animal Science 69 3321-3334.

Louhio H, Hovatta O, Sjöberg J \& Tuuri T 2000 The effects of insulin, and insulin-like growth factors I and II on human ovarian follicles in longterm culture. Molecular Human Reproduction 6 694-698. (doi:10.1093/ molehr/6.8.694)

Luo H, Kimura K, Aoki M \& Hirako M 2002 Effect of vascular endothelial growth factor on maturation, fertilization and developmental competence of bovine oocytes. Journal of Veterinary Medical Science $\mathbf{6 4}$ 803-806. (doi:10.1292/jvms.64.803)

Matos MH, Lima-Verde IB, Luque MC, Maia JE Jr, Silva JR, Celestino JJ, Martins FS, Báo SN, Lucci CM \& Figueiredo JR 2007 Essential role of follicle stimulating hormone in the maintenance of caprine preantral follicle viability in vitro. Zygote 15 173-182. (doi:10.1017/S0967199407004169)

Matzuk MM 2000 Revelations of ovarian follicle biology from gene knockout mice. Molecular and Cellular Endocrinology 163 61-66. (doi:10.1016/S0303-7207(99)00241-5)

McGee EA, Smith R, Spears N, Nachtigal MW, Ingraham H \& Hsueh AJ 2001 Müllerian inhibitory substance induces growth of rat preantral ovarian follicles. Biology of Reproduction 64 293-298. (doi:10.1095/ biolreprod64.1.293)

McNatty KP, Makris A, Osathanondh R \& Ryan KJ 1980 Effects of luteinizing hormone on steroidogenesis by thecal tissue from human ovarian follicles in vitro. Steroids 36 53-63. (doi:10.1016/0039128X(80)90067-7)
Miyano T \& Manabe N 2007 Oocyte growth and acquisition of meiotic competence. Society of Reproduction and Fertility Supplement 63 531-538.

Orisaka M, Orisaka S, Jiang JY, Craig J, Wang Y, Kotsuji F \& Tsang BK 2006 Growth differentiation factor 9 is antiapoptotic during follicular development from preantral to early antral stage. Molecular Endocrinology 20 2456-2468. (doi:10.1210/me.2005-0357)

Peters H 1979 The human ovary in childhood and early maturity. European Journal of Obstetrics, Gynecology, and Reproductive Biology 9 137-144.

Picton HM, Harris SE, Muruvi W \& Chambers EL 2008 The in vitro growth and maturation of follicles. Reproduction 136 703-715. (doi:10.1530/ REP-08-0290)

Rabin D, Spitz I, Bercovici B, Bell J, Laufer A, Benveniste R \& Polishuk W 1972 Isolated deficiency of follicle-stimulating hormone: clinical and laboratory features. New England Journal of Medicine 287 1313-1317. (doi:10.1056/NEJM197212282872602)

Ravindranath N, Little-Ihrig L, Phillips HS, Ferrara N \& Zeleznik AJ 1992 Vascular endothelial growth factor messenger ribonucleic acid expression in the primate ovary. Endocrinology 131 254-260. (doi:10.1210/en.131.1.254)

el-Roeiy A, Chen X, Roberts VJ, LeRoith D, Roberts CT Jr \& Yen SS 1993 Expression of insulin-like growth factor-I (IGF-I) and IGF-II and the IGF-I, IGF-II, and insulin receptor genes and localization of the gene products in the human ovary. Journal of Clinical Endocrinology and Metabolism 77 1411-1418. (doi:10.1210/jc.77.5.1411)

Samoto T, Maruo T, Ladines-Llave CA, Matsuo H, Deguchi J, Barnea ER \& Mochizuki M 1993 Insulin receptor expression in follicular and stromal compartments of the human ovary over the course of follicular growth, regression and atresia. Endocrine Journal 40 715-726. (doi:10.1507/ endocrj.40.715)

Schmidt KL, Kryger-Baggesen N, Byskov AG \& Andersen CY 2005 Anti-Müllerian hormone initiates growth of human primordial follicles in vitro. Molecular and Cellular Endocrinology 234 87-93. (doi:10.1016/ j.mce.2004.12.010)

Schoot DC, Harlin J, Shoham Z, Mannaerts BM, Lahlou N, Bouchard P, Bennink HJ \& Fauser BC 1994 Recombinant human follicle-stimulating hormone and ovarian response in gonadotrophin-deficient women. Human Reproduction 9 1237-1242.

Schramm RD, Tennier MT, Boatman DE \& Bavister BD 1993 Chromatin configurations and meiotic competence of oocytes are related to follicular diameter in nonstimulated rhesus monkeys. Biology of Reproduction 48 349-356. (doi:10.1095/biolreprod48.2.349)

Spears N, Murray AA, Allison V, Boland NI \& Gosden RG 1998 Role of gonadotrophins and ovarian steroids in the development of mouse follicles in vitro. Journal of Reproduction and Fertility 113 19-26. (doi:10.1530/jrf.0.1130019)

Stouffer RL, Martínez-Chequer JC, Molskness TA, Xu F \& Hazzard TM 2001 Regulation and action of angiogenic factors in the primate ovary. Archives of Medical Research 32 567-575. (doi:10.1016/S01884409(01)00323-X)

Tamura T, Kitawaki J, Yamamoto T, Osawa Y, Kominami S, Takemori S \& Okada H 1992 Immunohistochemical localization of 17 alphahydroxylase/C17-20 lyase and aromatase cytochrome P-450 in the human ovary during the menstrual cycle. Journal of Endocrinology 135 589-595. (doi:10.1677/joe.0.1350589)

Thomas FH, Telfer EE \& Fraser HM 2007 Expression of anti-Müllerian hormone protein during early follicular development in the primate ovary in vivo is influenced by suppression of gonadotropin secretion and inhibition of vascular endothelial growth factor. Endocrinology 148 2273-2281. (doi:10.1210/en.2006-1501)

Thompson WE, Asselin E, Branch A, Stiles JK, Sutovsky P, Lai L, Im GS, Prather RS, Isom SC, Rucker E III et al. 2004 Regulation of prohibitin expression during follicular development and atresia in the mammalian ovary. Biology of Reproduction 71 282-290. (doi:10.1095/biolreprod.103.024125)

Visser JA, Durlinger AL, Peters IJ, van den Heuvel ER, Rose UM, Kramer P, de Jong FH \& Themmen AP 2007 Increased oocyte degeneration and follicular atresia during the estrous cycle in anti-Müllerian hormone null mice. Endocrinology 148 2301-2308. (doi:10.1210/en.2006-1265)

Weenen C, Laven JS, Von Bergh AR, Cranfield M, Groome NP, Visser JA, Kramer P, Fauser BC \& Themmen AP 2004 Anti-Müllerian hormone expression pattern in the human ovary: potential implications for initial and cyclic follicle recruitment. Molecular Human Reproduction 10 77-83. (doi:10.1093/molehr/gah015) 
West ER, Xu M, Woodruff TK \& Shea LD 2007 Physical properties of alginate hydrogels and their effects on in vitro follicle development. Biomaterials 28 4439-4448. (doi:10.1016/j.biomaterials.2007.07.001)

West-Farrell ER, Xu M, Gomberg MA, Chow YH, Woodruff TK \& Shea LD 2009 The mouse follicle microenvironment regulates antrum formation and steroid production: alterations in gene expression profiles. Biology of Reproduction 80 432-439. (doi:10.1095/biolreprod.108.071142)

Wright CS, Hovatta O, Margara R, Trew G, Winston RM, Franks S \& Hardy K 1999 Effects of follicle-stimulating hormone and serum substitution on the in-vitro growth of human ovarian follicles. Human Reproduction 14 1555-1562. (doi:10.1093/humrep/14.6.1555)

Wu J, Nayudu PL, Kiesel PS \& Michelmann HW 2000 Luteinizing hormone has a stage-limited effect on preantral follicle development in vitro. Biology of Reproduction 63 320-327. (doi:10.1095/biolreprod63.1.320)

Xu M, Kreeger PK, Shea LD \& Woodruff TK 2006 Tissue-engineered follicles produce live, fertile offspring. Tissue Engineering 12 2739-2746. (doi:10. 1089/ten.2006.12.2739)

Xu M, West-Farrell ER, Stouffer RL, Shea LD, Woodruff TK \& Zelinski MB 2009a Encapsulated three-dimensional culture supports development of nonhuman primate secondary follicles. Biology of Reproduction $\mathbf{8 1}$ 587-594. (doi:10.1095/biolreprod.108.074732)

Xu M, Barrett SL, West-Farrell E, Kondapalli LA, Kiesewetter SE, Shea LD \& Woodruff TK $2009 \mathrm{~b}$ In vitro grown human ovarian follicles from cancer patients support oocyte growth. Human Reproduction 24 2531-2540. (doi:10.1093/humrep/dep228)
Yamamoto S, Konishi I, Tsuruta $Y$, Nanbu K, Mandai M, Kuroda H, Matsushita K, Hamid AA, Yura Y \& Mori T 1997 Expression of vascular endothelial growth factor (VEGF) during folliculogenesis and corpus luteum formation in the human ovary. Gynecological Endocrinology 11 371-381. (doi:10.3109/09513599709152564)

Yang S, He $X$, Niu $Y$, Hildebrandt TB, Jewgenow $K$, Goeritz F, Tang $X$, Chang Y, Zhou Q \& Ji W 2009 Ovarian response to gonadotropin stimulation in juvenile rhesus monkeys. Theriogenology 72 243-250. (doi:10.1016/j.theriogenology.2009.02.019)

Zelinski-Wooten MB, Hutchison JS, Hess DL, Wolf DP \& Stouffer RL 1995 Follicle stimulating hormone alone supports follicle growth and oocyte development in gonadotrophin-releasing hormone antagonist-treated monkeys. Human Reproduction 10 1658-1666.

Zheng P, Vassena R \& Latham KE 2007 Effects of in vitro oocyte maturation and embryo culture on the expression of glucose transporters, glucose metabolism and insulin signaling genes in rhesus monkey oocytes and preimplantation embryos. Molecular Human Reproduction 13 361-371. (doi:10.1093/molehr/gam014)

Received 22 June 2010

First decision 19 August 2010

Accepted 19 August 2010 